\title{
Catalytic Conversion of Dihydroxyacetone to Lactic Acid with Brønsted Acids and Multivalent Metal Ions
}

\author{
S. Lux ${ }^{*}$ and M. Siebenhofer \\ Graz University of Technology, Institute of Chemical Engineering \\ and Environmental Technology, NAWI Graz, \\ Inffeldgasse 25C, $8010 \mathrm{Graz}$, Austria
}

doi: 10.15255/CABEQ.2014.2110

Original scientific paper

Received: September 11, 2014

Accepted: November 26, 2015

The exploitation of by-products from chemical processes shows high potential for the development of new synthesis routes for valuable chemicals. Glycerol, provided as a by-product from the biodiesel manufacturing process, is a potential feedstock chemical. From dihydroxyacetone, a primary oxidation product of glycerol, lactic acid may be obtained. The catalytic effect of Brønsted acids and multivalent metal ions on the conversion of dihydroxyacetone to lactic acid in aqueous solutions was investigated. Lactic acid yields of $83 \%$ were achieved when carrying out the reaction under reflux boiling conditions with the catalyst $\mathrm{HCl}$ in excess. High acidity of the reaction solution is essential for the dehydration of dihydroxyacetone to pyruvic aldehyde. Consecutive conversion of pyruvic aldehyde to lactic acid was accelerated by multivalent metal ions (e.g. $\mathrm{Al}^{3+}$ ). The Lewis acid $\mathrm{Al}_{2}\left(\mathrm{SO}_{4}\right)_{3}$ provides both acidic reaction conditions for dehydration of dihydroxyacetone to pyruvic aldehyde and acceleration of lactic acid formation from pyruvic aldehyde. Lactic acid yields of up to $78 \%$ were obtained with $\mathrm{Al}_{2}\left(\mathrm{SO}_{4}\right)_{3}$.

Key words:

lactic acid, Brønsted acid, Lewis acid, dihydroxyacetone, glycerol

\section{Introduction}

At present, a vast majority of products such as plastics, cosmetics or pharmaceuticals are still petroleum-based. A shift towards renewable bio-based feedstock will be inevitable in the future. However, the use of biomass for chemical production implicates the redesign of existing processes and involves new challenges. Handling of aqueous reaction systems and the need for adapted separation techniques from aqueous solutions come to the fore. Retrieval of biomass which does not compete with the food production draws attention to the exploitation of residual materials. Glycerol (propane-1,2,3-triol) is a versatile molecule obtained as a by-product in the biodiesel manufacturing process. Due to increasing biodiesel production over the last decades, it may be regarded as a potential renewable feedstock chemical. Exploitation of glycerol for the production of lactic acid is a promising approach.

Lactic acid (2-hydroxypropionic acid) is emerging as a building block in a new generation of biobased materials. With both a hydroxyl and a carboxylic acid group, lactic acid may undergo many reactions. It therefore represents a central feedstock for the chemical industry, e.g., in the production of propylene glycol, acrylic acid or different condensation products. Besides applications in the food

"Corresponding author: susanne.lux@tugraz.at and cosmetics industries, growth in demand is expected due to expanding polymer markets (biodegradable synthetics) and elevated demand in the chemical sector due to ecologically friendly solvents and oxygenated chemicals. ${ }^{1,2}$ Nevertheless, commercial success depends on the development of an effective production method for highly pure lactic acid from abundant non-food biomass.

Oxidation of one of the three alcoholic functions of glycerol gives access to the synthesis of the trioses dihydroxyacetone (1,3-dihydroxypropan-2-one, DHA) and glyceraldehyde (2,3-dihydroxypropanal, GLAH), which may further be catalytically converted to lactic acid.

Dihydroxyacetone from glycerol is accessible via different synthesis routes. Chemical synthesis involves liquid phase self-condensation of formaldehyde with thiazolium catalysts. ${ }^{3}$ Much research has been done in the area of noble metal catalysed oxidation of glycerol. ${ }^{4-6}$ Partial electrochemical oxidation of glycerol to dihydroxyacetone is carried out with different electrode types in neutral ${ }^{7}$, alkaline $^{8-11}$ and acidic media ${ }^{10,11}$. The first microbiological dehydration of glycerol to dihydroxyacetone was reported in 1898 by Bertrand. ${ }^{12}$ Since then, several routes for microbiological synthesis of dihydroxyacetone have been developed and patented. Mainly vinegar bacteria type Acetobacter and Gluconobacter are used. ${ }^{13,14}$ 
<smiles>O=C(CO)CO</smiles><smiles>C=C</smiles><smiles></smiles>

Scheme 1 - Conversion of dihydroxyacetone (DHA) and glyceraldehyde (GLAH) to lactic acid (LA)

Non-fermentative catalytic chemical conversion of dihydroxyacetone and glyceraldehyde to lactic acid or lactate is currently gaining great interest in both academia and industry. The reaction proceeds via dehydration of the triose yielding pyruvic aldehyde (2-oxopropanal, PA) as intermediate (Scheme 1). Subsequent conversion of pyruvic aldehyde to lactic acid is an intramolecular Cannizzaro type rearrangement reaction. The key reaction step is the shift of a hydride. ${ }^{15}$

Conversion properties of dihydroxyacetone to pyruvic aldehyde under acid exposure were first mentioned by Pinkus ${ }^{16}$ in 1898 . Prey et al. ${ }^{15}$ reported the formation of lactic acid when treating dihydroxyacetone, glyceraldehyde and pyruvic aldehyde with acids. Acid catalysed isomerization of glyceraldehyde and dihydroxyacetone and dehydration to pyruvic aldehyde were investigated by Lookhart and Feather ${ }^{17}$. Strongly acidic operating conditions favour dehydration. The rate of dihydroxyacetone dehydration is higher than the rate of glyceraldehyde dehydration.

The use of heterogeneous Brønsted and Lewis acid catalysts and the use of homogeneous multivalent metal salts as catalysts have been reported in literature. Heterogeneous catalysts include zeolites $^{18}$, hydroxyapatite-supported Lewis acids ${ }^{19}$, substituted mesoporous MCM-41 materials ${ }^{20}$, and tin ion-exchanged montmorillonite ${ }^{21}$. Their application is limited to lactate synthesis in alcoholic medium as coking and irreversible structural modifications occur in aqueous solutions. These result in deactivation of the heterogeneous catalysts when the reaction is carried out in water for lactic acid synthesis. ${ }^{18,20}$ For the exploitation of biomass derived precursors, the handling of aqueous reaction systems is crucial.
Bicker et al. ${ }^{22}$ investigated the catalytic effect of the metal ions $\mathrm{Co}^{2+}, \mathrm{Ni}^{2+}, \mathrm{Cu}^{2+}$, and $\mathrm{Zn}^{2+}$ on the formation of lactic acid from hexoses and trioses in sub- and supercritical water. $\mathrm{Zn}^{2+}$ gave the best results with a lactic acid yield of $86 \%\left(\mathrm{~g} \mathrm{~g}^{-1}\right)$ from dihydroxyacetone at $300{ }^{\circ} \mathrm{C}(p=25 \mathrm{MPa})$. Rasrendra et $a l .{ }^{23}$ presented a study of the catalytic effect of 26 metal salts on the conversion of dihydroxyacetone and glyceraldehyde to lactic acid in water. A temperature range of $120-180^{\circ} \mathrm{C}$ was investigated. $\mathrm{Al}^{3+}$ salts were identified as the most promising catalysts with lactic acid yields of $>90 \%$ at $140{ }^{\circ} \mathrm{C}$ and a reaction time of 90 minutes.

These studies highlight that both acids and multivalent metal ions are capable of catalysing lactic acid formation from dihydroxyacetone. However, an investigation of liquid phase synthesis of lactic acid from dihydroxyacetone at moderate temperatures (room temperature to reflux boiling conditions at ambient pressure) is still lacking. Apart from potential energy savings and equipment simplifications, by-product formation is generally reduced or even suppressed at lower reaction temperatures. For this reason, an extensive study on liquid phase conversion of dihydroxyacetone to lactic acid in aqueous solution was conducted. The Brønsted acids $\mathrm{HCl}, \mathrm{H}_{2} \mathrm{SO}_{4}, \mathrm{H}_{3} \mathrm{PO}_{3}$, the strongly acidic ion exchange resin Lewatit ${ }^{\mathbb{B}} \mathrm{K} 2620$, and acidic hydrolysing metal salts were used as catalysts. The investigation of the conversion behaviour of dihydroxyacetone in acidic aqueous medium is especially relevant, as biomass derived precursors are often obtained after acid treatment of biomass. Consequently, both water and acid are present in the reaction solution. Furthermore, concurrence of homogeneous Brønsted acids with multivalent metal ions was discussed. The reaction kinetics with different catalysts was modelled and the most promising catalyst was identified. 


\section{Experimental}

\section{Chemicals}

Dihydroxyacetone (dimer, puriss.) was supplied by Merck. Pyruvic aldehyde $\left(\sim 40 \%\right.$ in $\left.\mathrm{H}_{2} \mathrm{O}\right)$ was provided by Sigma-Aldrich. Lactic acid in aqueous solution $\left(1 \mathrm{~mol} \mathrm{~L}^{-1}\right)$ was provided by Riedel-de Haën. Hydrochloric acid ( $\mathrm{HCl}, 37 \%$, p.a.) and sulphuric acid $\left(\mathrm{H}_{2} \mathrm{SO}_{4}, 95 \%\right)$ were purchased from Carl Roth. $\mathrm{H}_{3} \mathrm{PO}_{4}(85 \%)$ was purchased from Merck. Metal salts $\mathrm{Al}_{2}\left(\mathrm{SO}_{4}\right)_{3} \cdot 16 \mathrm{H}_{2} \mathrm{O}(\geq 95 \%$, p.a. $)$ and $\mathrm{ZnSO}_{4} \cdot 7 \mathrm{H}_{2} \mathrm{O}(\geq 99.5 \%$, p.a. $)$ were supplied by Carl Roth, $\mathrm{SnCl}_{2} \cdot 2 \mathrm{H}_{2} \mathrm{O}(\geq 98 \%$, p.a. $), \mathrm{Al}\left(\mathrm{NO}_{3}\right)_{3} \cdot 9 \mathrm{H}_{2} \mathrm{O}$ $\left(\geq 98.5 \%\right.$, p.a.), $\mathrm{CrCl}_{2}(90 \%)$, and $\mathrm{ZrOCl}_{2} \cdot 8 \mathrm{H}_{2} \mathrm{O}$ ( $\geq 99 \%$, pro analysi) by Merck, $\mathrm{AlCl}_{3}(\geq 99.9 \%$ ) by Sigma Aldrich; $\mathrm{Cr}_{4}\left(\mathrm{SO}_{4}\right)_{5}(\mathrm{OH})_{2}(100 \%)$ by Riedel-de Haën; and $\mathrm{CuSO}_{4}$ (99 \%, pur) by Fluka. The ion exchange resin Lewatit ${ }^{\circledR} \mathrm{K} 2620$ (cation exchange capacity $\geq 5.2$ eq $\mathrm{kg}^{-1}$ ) was provided by Lanxess. All chemicals, except the ion exchange resin, were used without further pretreatment. The ion exchange resin was washed with deionized water until the supernatant liquid was colourless and the $\mathrm{pH}$ neutral. Then it was vacuum dried until its mass remained constant.

Aqueous solutions of dihydroxyacetone were prepared by dissolving dimeric dihydroxyacetone in deionized water. Dissolution results in the monomerisation of the dimeric form. ${ }^{24}$ In most experiments, the concentration of dihydroxyacetone was $50 \mathrm{~g} \mathrm{~L}^{-1}$ $\left(0.56 \mathrm{~mol} \mathrm{~L}^{-1}\right)$. This value is representative for dihydroxyacetone solutions derived from the fermentation of glycerol.

\section{Experimental setup}

Homogeneous catalytic experiments were carried out in batch mode in reactors $(500 \mathrm{~mL})$ equipped with a reflux condenser, heating coil, and magnetic stirrer (Heidolph MR 3003 control). Homogeneous catalysts included mineral acids and soluble metal salts. The reaction was started by admixture of preheated catalyst and feed solutions. The reaction temperature was controlled and kept constant throughout the reaction $\left( \pm 0.5^{\circ} \mathrm{C}\right)$.

For loading of Lewatit ${ }^{\mathbb{R}} \mathrm{K} 2620$ with $\mathrm{Al}^{3+}$, the sodium form of the macroreticular resin was used. The loading procedure included stirring of Lewatit ${ }^{\circledR} \mathrm{K} 2620$ in aqueous solutions of $\mathrm{Al}_{2}\left(\mathrm{SO}_{4}\right)_{3} \cdot 16 \mathrm{H}_{2} \mathrm{O}$ at room temperature for five hours, washing with deionised water and drying in a vacuum dryer until its mass remained constant. Excess of the metal ions $\mathrm{Al}^{3+}$ was assured. At least a threefold molar amount of $\mathrm{Al}^{3+}$ was provided per mole of functional resin site. This procedure was carried out twice.

Experiments with aluminium-laden Lewatit ${ }^{\mathbb{R}} \mathrm{K} 2620$ were carried out in batch mode in reac- tors $(2 \mathrm{~L})$ equipped with a reflux condenser, heating coil, and stirrer with a PTFE stirring blade. The reaction was started by admixture of the catalyst to the preheated feed. The reaction temperature was controlled and kept constant throughout the reaction $\left( \pm 0.5^{\circ} \mathrm{C}\right)$.

For reuse of the aluminium-laden resin, the resin was separated from the reaction mixture, washed with deionised water, vacuum dried and used again.

Experiments were replicated at least three to five times. Mean deviation of dihydroxyacetone, pyruvic aldehyde and lactic acid concentrations were below $3 \%$, respectively. Results are given as mean values.

\section{Analytics}

Dihydroxyacetone, the intermediate pyruvic aldehyde and the product lactic acid were quantitatively analysed by high-performance liquid chromatography (Ultimate 3000, Dionex). The substances were separated with the columns Rezex ROA Organic Acid $\mathrm{H}^{+}$(Phenomenex) and Acclaim OA (Dionex). Detection was carried out with a variable wavelength UV/VIS detector at $190 \mathrm{~nm}$ and $210 \mathrm{~nm}$ (Dionex). For elution of the substances from Rezex ROA $0.005 \mathrm{~mol} \mathrm{~L}^{-1} \mathrm{H}_{2} \mathrm{SO}_{4}$ at $50{ }^{\circ} \mathrm{C}$ was used. From Acclaim OA column substances were eluted with $0.1 \mathrm{~mol} \mathrm{~L}^{-1} \mathrm{Na}_{2} \mathrm{SO}_{4}$ (pH 2.65) at $30^{\circ} \mathrm{C}$. The $\mathrm{pH}$ was adjusted with methane sulphonic acid.

\section{Modelling of the reaction kinetics}

Lactic acid formation from dihydroxyacetone was formally best modelled as a dual step consecutive reaction. Both reaction steps are first order with respect to the corresponding educt. According to the mechanism shown in Equation 1, $k_{1}$ is the rate constant for the conversion of dihydroxyacetone to pyruvic aldehyde, $k_{2}$ the rate constant for the consecutive conversion of pyruvic aldehyde to lactic acid.

$$
\mathrm{DHA} \stackrel{k_{1}}{\rightarrow} \mathrm{PA} \stackrel{k_{2}}{\rightarrow} \text { LA }
$$

Kinetics of by-product formation was not modelled but taken into account through implementation of the selectivity factor $S$. $S$ represents the molar fraction of feed dihydroxyacetone, which is converted to pyruvic aldehyde and lactic acid via dehydration and Cannizzaro rearrangement, respectively.

The conversion of acetic acid was modelled according to Equation 2.

$$
c_{\mathrm{DHA}}=c_{\mathrm{DHA}, 0} \cdot e^{-k_{1} \cdot t}
$$

The rate constant $k_{1}$ was derived by minimizing the mean squared deviation of the calculated and 
the measured dihydroxyacetone concentrations. The formation and conversion of pyruvic aldehyde was modelled according to Equation 3. After determination of $k_{1}, k_{2}$ and $S_{\mathrm{PA}}$ were derived by the method of least squares with respect to calculated and experimental pyruvic aldehyde concentrations.

$$
c_{\mathrm{PA}}=\frac{c_{\mathrm{DHA}, 0} \cdot S_{\mathrm{PA}} \cdot k_{1}}{k_{2}-k_{1}} \cdot\left(e^{-k_{1} \cdot t}-e^{-k_{2} \cdot t}\right)
$$

Lactic acid formation was modelled according to Equation 4.

$$
\begin{gathered}
c_{\mathrm{LA}}=c_{\mathrm{DHA}, 0} \cdot S_{\mathrm{LA}} \cdot \\
\cdot\left[1+\frac{1}{k_{1}-k_{2}} \cdot\left(k_{2} \cdot e^{-k_{1} \cdot t}-k_{1} \cdot e^{-k_{2} \cdot t}\right)\right]
\end{gathered}
$$

With known rate constants $k_{1}$ and $k_{2}, S_{\mathrm{LA}}$ was derived by minimizing the mean squared deviation of the calculated and the measured concentrations of lactic acid.

Temperature dependence of $k_{1}$ and $k_{2}$ was based on Arrhenius' law (Equation 5).

$$
k=A \cdot \mathrm{e}^{-\frac{E_{\mathrm{A}}}{R \cdot T}}
$$

\section{Results and discussion}

\section{Catalysis with Brønsted acids}

The catalytic effect of the homogeneous Brønsted acids $\mathrm{HCl}, \mathrm{H}_{2} \mathrm{SO}_{4}$, and $\mathrm{H}_{3} \mathrm{PO}_{4}$ on the formation of lactic acid was investigated. The ion exchange resin Lewatit ${ }^{\circledR} \mathrm{K} 2620$ was used as a heterogeneous Brønsted acid catalyst. Moreover, the autocatalytic effect of lactic acid was screened.

\section{Comparison of different Brønsted acids}

For comparison of the catalytic effect of the Brønsted acids $\mathrm{HCl}, \mathrm{H}_{2} \mathrm{SO}_{4}$, and $\mathrm{H}_{3} \mathrm{PO}_{4}$ on the formation of lactic acid, experiments were performed at reflux boiling conditions with dihydroxyacetone concentrations of $0.56 \mathrm{~mol} \mathrm{~L}^{-1}$ and acid concentrations of $c_{\mathrm{H}^{+}}=1 \mathrm{~mol} \mathrm{~L}^{-1}$, respectively. For investigation of the autocatalytic effect of lactic acid, experiments were performed under the same reaction conditions $\left(c_{\mathrm{DHA}, 0}=0.56 \mathrm{~mol} \mathrm{~L} \mathrm{~L}^{-1}\right.$, reflux boiling conditions) and an initial lactic acid concentration of $1 \mathrm{~mol} \mathrm{~L}^{-1}$.

High acidity of the reaction solution results in fast conversion of dihydroxyacetone. As depicted from Table 1, the rate of dihydroxyacetone conversion increases with increased acidity.
Table 1 -Catalytic effect of different Brønsted acids on the conversion of dihydroxyacetone $\left(X_{D H A}\right)$ and the yields of pyruvic

\begin{tabular}{|c|c|c|c|c|c|c|}
\hline \multirow{2}{*}{ Catalyst } & $\begin{array}{c}X_{\mathrm{DHA}} \\
\%\end{array}$ & $\begin{array}{l}Y_{\mathrm{PA}} \\
\%\end{array}$ & $\begin{array}{c}Y_{\mathrm{LA}} \\
\%\end{array}$ & $\begin{array}{c}X_{\text {DHA }} \\
\%\end{array}$ & $\begin{array}{l}Y_{\mathrm{PA}} \\
\%\end{array}$ & $\begin{array}{l}Y_{\mathrm{LA}} \\
\%\end{array}$ \\
\hline & \multicolumn{3}{|c|}{$1 \mathrm{~h}$} & \multicolumn{3}{|c|}{$6 \mathrm{~h}$} \\
\hline Lactic acid $^{[\mathrm{a}]}$ & 9 & 7 & 2 & 39 & 26 & 4 \\
\hline $\mathrm{HCl}^{[\mathrm{a}]}$ & 100 & 87 & 7 & 100 & 54 & 30 \\
\hline $\mathrm{H}_{2} \mathrm{SO}_{4}{ }^{[\mathrm{a}]}$ & 100 & 87 & 4 & 100 & 54 & 19 \\
\hline $\mathrm{H}_{3} \mathrm{PO}_{4}{ }^{[\mathrm{a}]}$ & 32 & 23 & $\leq 0.1$ & 85 & 65 & 1 \\
\hline Lewatit ${ }^{\mathbb{R}} \mathrm{K} 2620^{[\mathrm{b}]}$ & 88 & 88 & $\leq 1$ & 100 & 72 & 28 \\
\hline
\end{tabular}
aldehyde $\left(Y_{P A}\right)$ and lactic acid $\left(Y_{L A}\right)$ after a reaction time of $1 \mathrm{~h}$

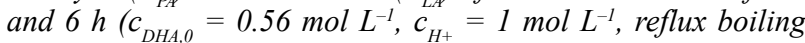
conditions)

With $\mathrm{HCl}$ and $\mathrm{H}_{2} \mathrm{SO}_{4}$ as the strongest acids, dihydroxyacetone was completely converted within one hour. The yields of lactic acid were $7 \%$ and $4 \%$, respectively. After a reaction time of six hours, lactic acid yields were $30 \%$ with $\mathrm{HCl}$ and $19 \%$ with $\mathrm{H}_{2} \mathrm{SO}_{4}$. From the results in Table 1, it can be depicted that after six hours, $16 \%$ of dihydroxyacetone must have reacted to unfavourable by-products when using $\mathrm{HCl}$ as catalyst. With $\mathrm{H}_{2} \mathrm{SO}_{4}, 27 \%$ of dihydroxyacetone (on a molar basis) must have been converted to by-products after six hours.

In contrast to complete conversion within one hour with $\mathrm{HCl}$ and $\mathrm{H}_{2} \mathrm{SO}_{4}$, only $32 \%$ of dihydroxyacetone were converted with $\mathrm{H}_{3} \mathrm{PO}_{4}$ and $88 \%$ with Lewatit ${ }^{\mathbb{R}} \mathrm{K} 2620$. Lactic acid was not formed in remarkable amounts $(\leq 1 \%)$ during that time. With $\mathrm{H}_{3} \mathrm{PO}_{4}$, the yield of lactic acid was still low $(1 \%)$ after six hours, whereas with Lewatit ${ }^{\mathbb{}} \mathrm{K} 2620$ yields of $28 \%$ could be achieved. Limited lactic acid yields of $28 \%$ are dedicated to the lower rates of reaction with Lewatit ${ }^{\mathbb{R}} \mathrm{K} 2620$. According to the material balance, no by-product formation was observed during a reaction time of six hours. Furthermore, easy separation from the reaction mixture and reusability of Lewatit ${ }^{\mathbb{}} \mathrm{K} 2620$ are advantageous. No loss of catalytic activity was observed after repeated use under the conditions specified (six times for six hours).

The autocatalytic effect of lactic acid on the conversion of dihydroxyacetone was also investigated. After one hour, $9 \%$ of dihydroxyacetone were converted when lactic acid was present in the feed solution. Due to its lower acidity, the yields of lactic acid were limited to $2 \%$ after a reaction time of one hour.

This shows the high impact of acidity on the rates of conversion. High acidity of the reaction solution favours both conversion of dihydroxyacetone and consecutive rearrangement of pyruvic al- 
dehyde to lactic acid. Highest lactic acid yields were achieved with $\mathrm{HCl}$ due to its high acidity. Since the highest reaction rates and higher selectivities towards lactic acid in contrast to the catalyst $\mathrm{H}_{2} \mathrm{SO}_{4}$ were achieved with $\mathrm{HCl}$, further investigations were based on $\mathrm{HCl}$ as catalyst.

\section{Catalysis with $\mathrm{HCl}$}

Figure 1 representatively shows the conversion of dihydroxyacetone to lactic acid via the intermediate pyruvic aldehyde with $\mathrm{HCl}$. Dihydroxyacetone was completely converted within 10 minutes when carrying out the reaction with $3 \mathrm{~mol} \mathrm{~L}^{-1} \mathrm{HCl}$ and boiling under reflux conditions. Subsequent conversion of the intermediate pyruvic aldehyde to lactic acid was rate determining. The rate of lactic acid formation was low at the beginning. This period of induction is characteristic for consecutive reactions. Isomeric glyceraldehyde was not detected in remarkable amounts.

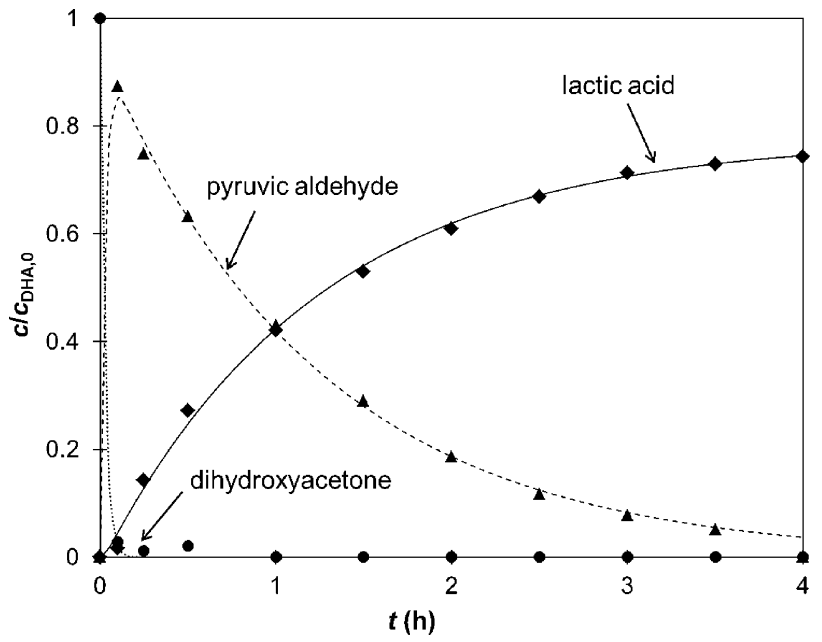

Fig. 1 - Conversion of dihydroxyacetone to lactic acid via the intermediate pyruvic aldehyde with $\mathrm{HCl}\left(c_{D H 40}=0.56 \mathrm{~mol} \mathrm{~L} \mathrm{~L}^{-1}\right.$, $c_{H C l}=3 \mathrm{~mol} \mathrm{~L}^{-1}$, boiling at reflux conditions, ambient pressure)

With $\mathrm{HCl}$, the transparent reaction solution changed colour to yellow and brownish with progress in reaction. Polymerized pyruvic aldehyde is assumed to be responsible for the change in colour. Dark brown to black precipitates segregated at high acid concentrations and high reaction temperatures. This was also observed for catalysis with $\mathrm{H}_{2} \mathrm{SO}_{4}$ and $\mathrm{H}_{3} \mathrm{PO}_{4}$. Hahn and Schales ${ }^{25}$ described precipitates similar to the species found in this project as segregated acids with humic acid-like properties.

\section{Effect of reaction temperature}

The liquid-phase conversion of dihydroxyacetone to lactic acid with $\mathrm{HCl}$ was investigated in a temperature range of $25^{\circ} \mathrm{C}$ to $100{ }^{\circ} \mathrm{C}$. The yield of lactic acid at different reaction temperatures can be

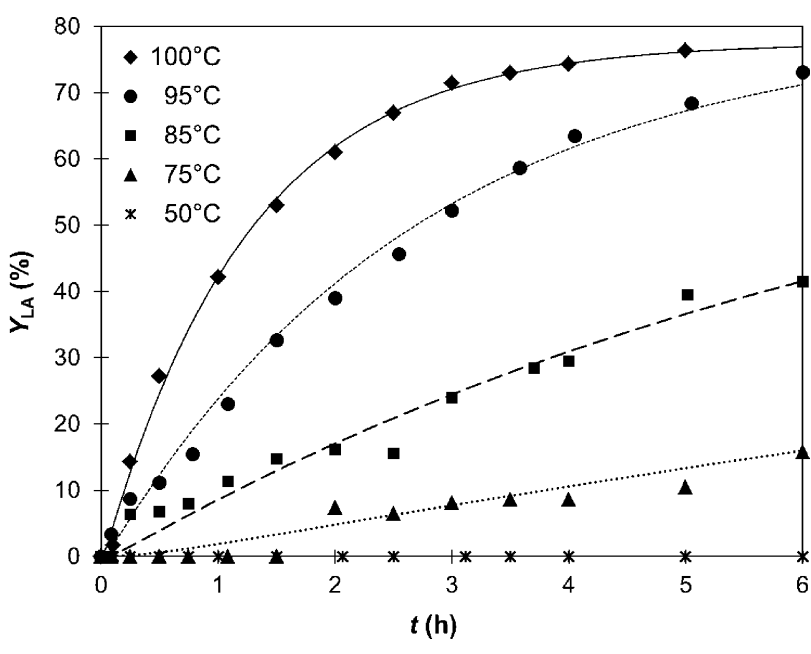

Fig. 2 - Effect of the reaction temperature on the yield of lactic acid (LA) with $\mathrm{HCl}\left(c_{D H A, 0}=0.56 \mathrm{~mol} \mathrm{~L}^{-1}\right.$, $c_{H C l}=3 \mathrm{~mol} \mathrm{~L}^{-1}$ )

depicted from Figure 2. The effect of the reaction temperature on intermediate formation of pyruvic aldehyde and its consecutive conversion can be seen in Figure 3. The initial dihydroxyacetone concentration was $0.56 \mathrm{~mol} \mathrm{~L}^{-1}$ in those experiments; $\mathrm{HCl}$ concentration was $3 \mathrm{~mol} \mathrm{~L}^{-1}$.

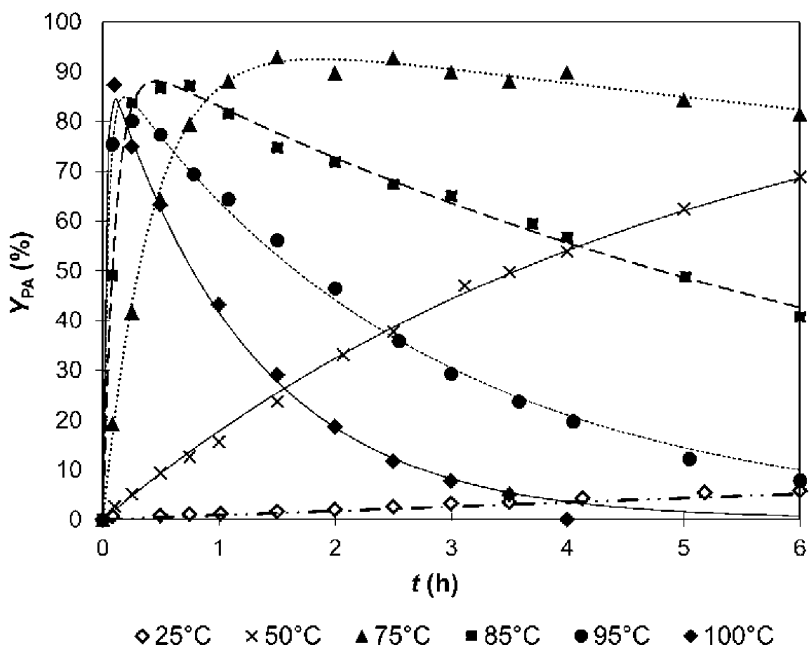

Fig. 3 - Effect of the reaction temperature on the yield of pyruvic aldehyde (PA) with $\mathrm{HCl}\left(c_{D H A, O}=0.56 \mathrm{~mol} \mathrm{~L}^{-1}\right.$, $c_{\mathrm{HCl}}=3 \mathrm{~mol} \mathrm{~L}^{-1}$ )

The yield of lactic acid increased significantly with increasing reaction temperatures. No lactic acid formation was observed for six hours when carrying out the reaction below $50{ }^{\circ} \mathrm{C}$. As expected from the negligible lactic acid formation, formation of pyruvic aldehyde was suppressed at low temperatures $\left(25^{\circ} \mathrm{C}\right)$, too. The yield of pyruvic aldehyde was less than $6 \%$ after six hours at $25^{\circ} \mathrm{C}$. At $50{ }^{\circ} \mathrm{C}, 70 \%$ of dihydroxyacetone was converted after six hours. A yield of $70 \%$ of pyruvic aldehyde after six hours showed that by-product formation 
from dihydroxyacetone was negligible at these reaction conditions resulting in complete conversion of dihydroxyacetone to pyruvic aldehyde. However, lactic acid formation was suppressed due to the low reaction temperature.

At $75{ }^{\circ} \mathrm{C}$, the yield of lactic acid was still low $(16 \%)$ after six hours. A remaining pyruvic aldehyde concentration of $0.46 \mathrm{~mol} \mathrm{~L}^{-1}$ and complete conversion of dihydroxyacetone within 2.5 hours indicated that by-product formation was still of minor relevance (below $2 \%$ ).

Complete conversion of dihydroxyacetone was achieved within 45 minutes at $85^{\circ} \mathrm{C}$ and within 10 minutes at $100{ }^{\circ} \mathrm{C}$. At $100{ }^{\circ} \mathrm{C}$, the peak pyruvic aldehyde concentration was obtained within 5 minutes. Consecutive rearrangement to lactic acid was completed within 6 hours. The yield of lactic acid was $78 \%$.

The temperature dependency was modelled according to Arrhenius' law (Figure 4). Table 2 lists the activation energies $E_{\mathrm{A}}$ and pre-exponential factors $A$ for both reaction steps. Activation energies and the pre-exponential factors confirm that lactic acid formation from pyruvic aldehyde is rate-determining. From the Arrhenius' plot, no change of reaction mechanism within the investigated temperature range could be deduced.

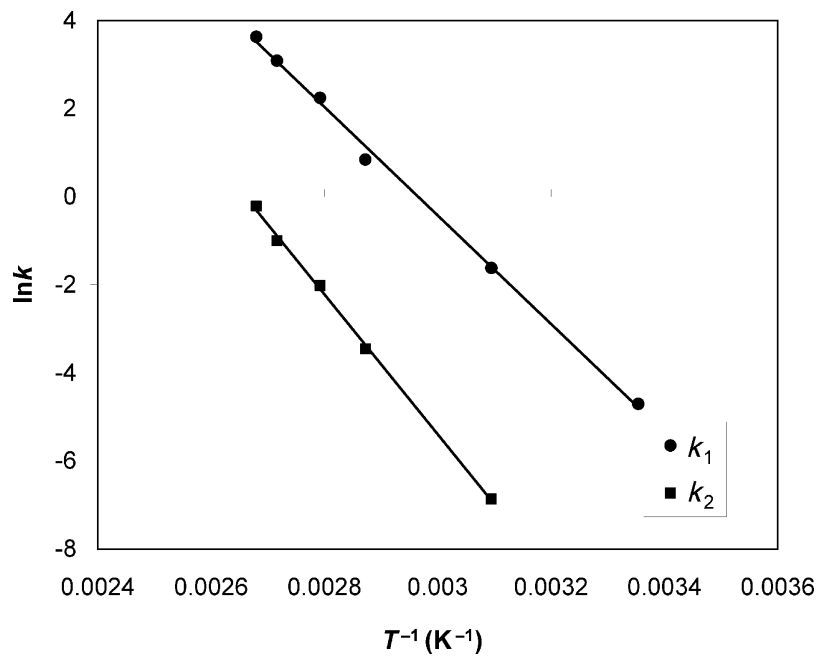

Fig. 4 - Arrhenius' plot for the first (dihydroxyacetone to pyruvic aldehyde) and second (pyruvic aldehyde to lactic acid) reaction step $\left(c_{H C l}=3 \mathrm{~mol} \mathrm{~L}^{-1}, c_{D H A, 0}=0.56 \mathrm{~mol} \mathrm{~L}^{-1}\right)$

Table 2 -Activation energies $E_{A}$ and pre-exponential factors A for the $\mathrm{HCl}$ catalysed conversion of dihydroxyacetone to lactic acid $\left(c_{H C l}=3 \mathrm{~mol} \mathrm{~L}^{-1}, c_{D H A, 0}=0.56 \mathrm{~mol} \mathrm{~L}^{-1}\right)$

\begin{tabular}{l|c|c}
\hline & $A\left(\mathrm{~h}^{-1}\right)$ & $E_{\mathrm{A}}\left(\mathrm{kJ} \mathrm{mol}^{-1}\right)$ \\
\hline $1 . \mathrm{DHA} \rightarrow$ PA & $(7.29 \pm 0.02) \cdot 10^{15}$ & $102.4 \pm 0.3$ \\
$2 . \mathrm{PA} \rightarrow \mathrm{LA}$ & $(2.35 \pm 0.01) \cdot 10^{18}$ & $132.2 \pm 0.4$ \\
\hline
\end{tabular}

Effect of $\mathrm{HCl}$ and feed dihydroxyacetone concentrations

At a fixed feed dihydroxyacetone concentration of $0.56 \mathrm{~mol} \mathrm{~L}^{-1} \mathrm{HCl}$ concentrations were varied between $0.5 \mathrm{~mol} \mathrm{~L}^{-1}$ and $5 \mathrm{~mol} \mathrm{~L}^{-1}$, respectively. According to the $\mathrm{HCl}$ concentrations in the solution, a boiling point temperature between $98{ }^{\circ} \mathrm{C}$ and $104{ }^{\circ} \mathrm{C}$ was observed.

Figure 5 shows the strong impact of the acidity of the reaction solution on the rate of lactic acid formation again.

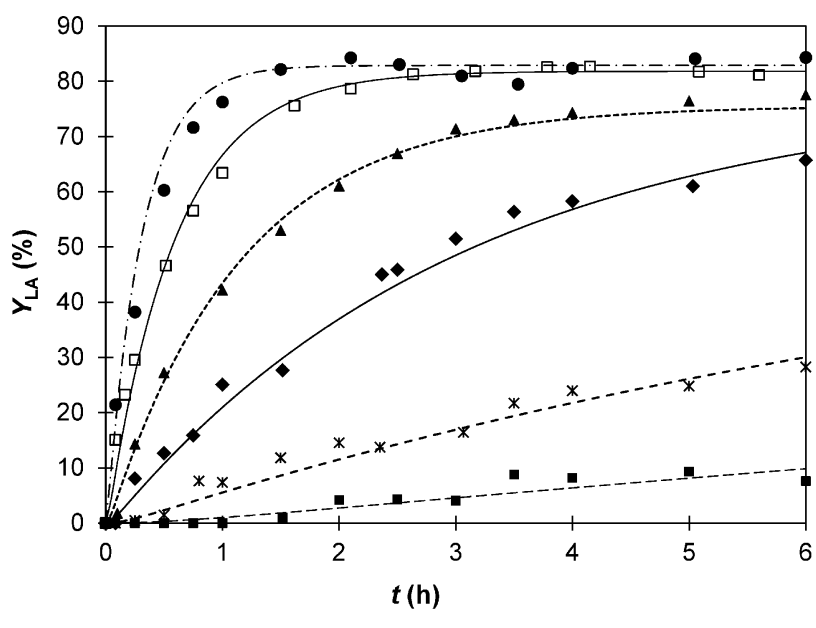

- $0.5 \mathrm{~mol} \mathrm{~L}^{-1} * 1 \mathrm{~mol} \mathrm{~L}^{-1} \bullet 2 \mathrm{~mol} \mathrm{~L}^{-1} \triangleleft 3 \mathrm{~mol} \mathrm{~L}^{-1} \square 4 \mathrm{~mol} \mathrm{~L}^{-1} \bullet 5 \mathrm{~mol} \mathrm{~L}^{-1}$

$\mathrm{Fig} .5$ - Effect of $\mathrm{HCl}$ concentrations on the yield of lactic acid at operation under reflux boiling conditions $\left(c_{D H A .0}=0.56 \mathrm{~mol} \mathrm{~L}^{-1}\right.$; $98^{\circ} \mathrm{C}\left(c_{\mathrm{HCl}}=0.5 \mathrm{~mol} \mathrm{~L}^{-1}\right), 99^{\circ} \mathrm{C}\left(c_{\mathrm{HCl}}=1 \mathrm{~mol} \mathrm{~L}-1\right), 100^{\circ} \mathrm{C}\left(c_{\mathrm{HCl}}\right.$ $\left.=2 \mathrm{~mol} \mathrm{~L}{ }^{-1}\right), 101{ }^{\circ} \mathrm{C}\left(c_{\mathrm{HCl}}=3 \mathrm{~mol} \mathrm{~L} L^{-1}\right), 103{ }^{\circ} \mathrm{C}\left(c_{\mathrm{HCl}}=4 \mathrm{~mol} \mathrm{~L} \mathrm{~L}^{-1}\right)$ and $\left.104^{\circ} \mathrm{C}\left(c_{\mathrm{HCl}}=5 \mathrm{~mol} \mathrm{~L}{ }^{-1}\right)\right)$

$\mathrm{HCl}$ concentrations of $0.5 \mathrm{~mol} \mathrm{~L}^{-1}$ resulted in complete conversion of dihydroxyacetone within three hours. The results indicated that dihydroxyacetone was entirely converted to pyruvic aldehyde. Increasing $\mathrm{HCl}$ concentrations to $1 \mathrm{~mol} \mathrm{~L}^{-1}$ reduced the time for complete conversion of dihydroxyacetone to one hour. With $\mathrm{HCl}$ in a concentration of $5 \mathrm{~mol} \mathrm{~L}^{-1}$ complete dihydroxyacetone conversion was achieved within 5 minutes.

Apart from higher reaction rates, increasing $\mathrm{HCl}$ concentrations resulted in increasing lactic acid selectivity. This indicates that by-product formation from pyruvic aldehyde is suppressed at high acid concentrations. With $5 \mathrm{~mol} \mathrm{~L}-1$ HCl, the final lactic acid yield was $83 \%$. Subsequent degradation of lactic acid was not observed.

The validity of the rate law for different dihydroxyacetone concentrations was investigated from $25 \mathrm{~g} \mathrm{~L}^{-1}\left(0.28 \mathrm{~mol} \mathrm{~L}^{-1}\right)$ to $75 \mathrm{~g} \mathrm{~L}^{-1}\left(0.83 \mathrm{~mol} \mathrm{~L}^{-1}\right)$ and a constant $\mathrm{HCl}$ concentration of $3 \mathrm{~mol} \mathrm{~L}^{-1}$ at $101{ }^{\circ} \mathrm{C}$. In a second series of experiments, the validity of the rate law was tested for varying feed dihydroxyacetone concentrations but constant 5.4-fold 
molar excess of $\mathrm{H}^{+}$with respect to feed dihydroxyacetone at $101^{\circ} \mathrm{C}$.

Again, it was confirmed that the $\mathrm{HCl}$ concentration in the aqueous solution has a major impact on the rate of lactic acid formation. Acidity of the reaction mixture consequently has a high impact on lactic acid formation. Highest lactic acid formation rates were obtained at high $\mathrm{HCl}$ concentrations. With $75 \mathrm{~g} \mathrm{~L}^{-1}$ dihydroxyacetone and $4.5 \mathrm{~g} \mathrm{~L}^{-1} \mathrm{HCl}$ in the feed, the yield of lactic acid was $50 \%$ after 30 minutes and a final lactic acid yield of $78 \%$ was achieved within three hours. After three hours, the yield of lactic acid was $71 \%$ with $50 \mathrm{~g} \mathrm{~L}^{-1}$ dihydroxyacetone and $3 \mathrm{~mol} \mathrm{~L}^{-1} \mathrm{HCl}$ in the feed, and $36 \%$ with $25 \mathrm{~g} \mathrm{~L}^{-1}$ dihydroxyacetone and $1.5 \mathrm{~mol} \mathrm{~L}^{-1}$ $\mathrm{HCl}$.

At constant $\mathrm{HCl}$ concentration and varying feed dihydroxyacetone concentrations, the yield of lactic acid decreases with increasing dihydroxyacetone concentration. By material balance, the portion of dihydroxyacetone which was converted to pyruvic aldehyde and lactic acid, respectively, was determined. With $25 \mathrm{~g} \mathrm{~L}^{-1}$ feed dihydroxyacetone 87 $\%$ of dihydroxyacetone were converted to pyruvic aldehyde and lactic acid after a reaction time of six hours. In contrast to this, the percentage was lower with $50 \mathrm{~g} \mathrm{~L}^{-1}(77 \%)$ and $75 \mathrm{~g} \mathrm{~L}^{-1}(75 \%)$.

\section{Concurrence of Bronsted acid catalysts and multivalent metal ions}

Experiments with multivalent metal ions $\mathrm{Zn}^{2+}$, $\mathrm{Sn}^{2+}, \mathrm{Fe}^{2+}, \mathrm{Fe}^{3+}, \mathrm{Al}^{3+}, \mathrm{Cr}^{2+}$, and $\mathrm{Cr}^{3+}$ revealed different catalytic effects on the acid catalysed conversion of dihydroxyacetone to lactic acid. Experiments were performed with $0.56 \mathrm{~mol} \mathrm{~L}^{-1}$ feed concentrations of dihydroxyacetone, acid concentrations of $1 \mathrm{~mol} \mathrm{H}^{+} \mathrm{L}^{-1}$ plus catalytic amounts of metal ions at $99{ }^{\circ} \mathrm{C}$. The conversion of dihydroxyacetone and yields of pyruvic aldehyde and lactic acid are compared in Table 3 for the various metal salts after a reaction time of one hour.

For combinations of Brønsted acids and metal ions, the highest catalytic effect on lactic acid formation was observed with $\mathrm{Sn}^{2+}$. With $\mathrm{HCl} / \mathrm{Sn}^{2+}$ both dihydroxyacetone and pyruvic aldehyde were completely converted within one hour. A final lactic acid yield of $75 \%$ was achieved after one hour. In contrast, the yield of lactic acid after one hour was $7 \%$ for $\mathrm{HCl}$ catalysis without $\mathrm{Sn}^{2+}$. It was shown that the addition of catalytic amounts of $\mathrm{Sn}^{2+}$ to the $\mathrm{HCl}$ catalysed reaction had a significant catalytic impact on lactic acid formation. Nevertheless, $\mathrm{Sn}^{2+}$ in aqueous solution hydrolyses and precipitates. Hydrolysis was not suppressed with $\mathrm{HCl}$ or $\mathrm{H}_{2} \mathrm{SO}_{4}$ in the corresponding concentration range.
Table 3 -Catalytic effect of Brønsted acids with multivalent metal ions on lactic acid formation from dihydroxyacetone

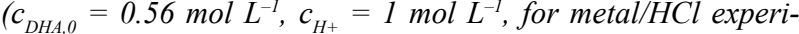
ments: $c_{M e}=0.06 \mathrm{~mol} \mathrm{~L}{ }^{-1}, 99{ }^{\circ} \mathrm{C}$, reaction time: $1 \mathrm{~h}$ ).

\begin{tabular}{ccc|c|c|c}
\hline acid & $\mathrm{Me}$ & $\begin{array}{c}X_{\mathrm{DHA}} \\
\%\end{array}$ & $\begin{array}{c}Y_{\mathrm{PA}} \\
\%\end{array}$ & $\begin{array}{c}Y_{\mathrm{LA}} \\
\%\end{array}$ & $\begin{array}{c}Y_{\mathrm{LA}}{ }^{[\mathrm{cc}]} \\
\%\end{array}$ \\
\hline $\mathrm{HCl}$ & $\mathrm{Zn}^{2+}$ & 100 & 70 & 5 & 23 \\
$\mathrm{HCl}$ & $\mathrm{Sn}^{2+}$ & 100 & $\leq 0.1$ & 75 & 75 \\
$\mathrm{HCl}$ & $\mathrm{Fe}^{2+}$ & $\geq 99.9$ & 84 & 7 & 26 \\
$\mathrm{HCl}$ & $\mathrm{Fe}^{3+}$ & $\geq 99.9$ & 77 & 4 & 23 \\
$\mathrm{HCl}$ & $\mathrm{Al}^{3+}$ & $\geq 99.9$ & 74 & 24 & 51 \\
$\mathrm{HCl}$ & $\mathrm{Cr}^{2+}$ & $\geq 99.9$ & 48 & 46 & 91 \\
$\mathrm{HCl}$ & $\mathrm{Cr}^{3+}$ & $\geq 99.9$ & 45 & 40 & 91 \\
Lewatit ${ }^{\mathbb{}} \mathrm{K} 2620^{[\mathrm{a}]}$ & $\mathrm{Al}^{3+[b]}$ & 42 & 20 & 8 & 73 \\
Lewatit ${ }^{\mathbb{}} \mathrm{K} 2620^{[\mathrm{a}]}$ & $\mathrm{Cr}^{3+[b]}$ & 67 & 13 & 31 & 89 \\
\hline
\end{tabular}

${ }^{[\mathrm{a}]} 98^{\circ} \mathrm{C}{ }^{[\mathrm{b}]}$ doped ${ }^{[\mathrm{cc}]}$ reaction time: $6 \mathrm{~h}$

With $\mathrm{Al}^{3+} / \mathrm{HCl}$, the lactic acid yield was $24 \%$ after one hour, and $51 \%$ after six hours. $\mathrm{Al}^{3+}$ had an accelerating effect on lactic acid formation without the negative side effect of precipitation.

Admixture of $\mathrm{Zn}^{2+}, \mathrm{Fe}^{2+}$, and $\mathrm{Fe}^{3+}$ had a negative impact on lactic acid formation. Even though, conversion of dihydroxyacetone was comparable for $\mathrm{Al}^{3+}$ and $\mathrm{Zn}^{2+}$, admixture of $\mathrm{Zn}^{2+}$ resulted in increased formation of unidentified by-products. Low yields of pyruvic aldehyde with $\mathrm{Zn}^{2+}$ indicated that by-product formation was favoured. Yields of lactic acid were higher with $\mathrm{Fe}^{2+}$ than with $\mathrm{Fe}^{3+}$ or $\mathrm{Zn}^{2+}$.

The highest catalytic effect on lactic acid formation was achieved with $\mathrm{Cr}^{2+} / \mathrm{HCl}$ and $\mathrm{Cr}^{3+} / \mathrm{HCl}$.

Doping of Lewatit ${ }^{\mathbb{B}} \mathrm{K} 2620$ with $\mathrm{Al}^{3+}$ and $\mathrm{Cr}^{3+}$ showed a high catalytic effect on lactic acid formation, too. The lactic acid yields were $73 \%$ and $89 \%$ after six hours with $\mathrm{Al}^{3+}$ and $\mathrm{Cr}^{3+}$-doped Lewatit ${ }^{\mathbb{R}} \mathrm{K} 2620$. The yield was limited to $14 \%$ with nondoped Lewatit ${ }^{\mathbb{R}} \mathrm{K} 2620$. Conversion rates of dihydroxyacetone were lower with both non-doped and doped Lewatit ${ }^{\mathbb{R}} \mathrm{K} 2620$ with respect to the $\mathrm{HCl}$ catalysed reaction. This confirms that dihydroxyacetone dehydration requires strongly acidic reaction conditions, not provided by the specific ion-exchange resin.

The higher yields with $\mathrm{Al}^{3+}$-doped Lewatit ${ }^{\circledR} \mathrm{K} 2620$ (73\% after six hours) with respect to $\mathrm{Al}^{3+} / \mathrm{HCl}(51 \%)$ may be attributed to the higher concentrations of metal ions due to doping. However, reusability of metal-doped Lewatit ${ }^{\mathbb{B}} \mathrm{K} 2620$ was unsatisfactory. Lactic acid yields after six hours dropped to $61 \%$ after reuse of $\mathrm{Al}^{3+}$-doped Lewa$\mathrm{tit}^{\mathbb{}} \mathrm{K} 2620$. Aluminium, detected in the reaction solution, confirmed that the stability of the $\mathrm{Al}^{3+}$-laden resin was unsatisfactory. Limited stability of 
metal-doped Lewatit ${ }^{\circledR} \mathrm{K} 2620$ and toxicity of chromium were unfavourable for $\mathrm{Cr}^{3+}$ catalyst.

In Figure 6, dihydroxyacetone conversion, formation of the intermediate pyruvic aldehyde and the product lactic acid are compared for $\mathrm{HCl}$ catalysed and $\mathrm{HCl} / \mathrm{Al}^{3+}$ catalysed reaction. Dihydroxyacetone conversion was comparable for both catalysts. Admixture of catalytic amounts of $\mathrm{Al}^{3+}$ had a high accelerating impact on the rate determining conversion of pyruvic aldehyde. This selective acceleration of lactic acid formation from pyruvic aldehyde may be attributed to chelat complexes formed of pyruvic aldehyde and $\mathrm{Al}^{3+} .{ }^{26}$ Bicker et al. ${ }^{22}$ proposed that an inversion of the polarity of the Lewis acid to a Lewis base for metal ions could occur. The latter is able to form a complex between pyruvic aldehyde and the metal ion. Then rehydration of this complex leads to the formation of lactic acid and the free catalyst.

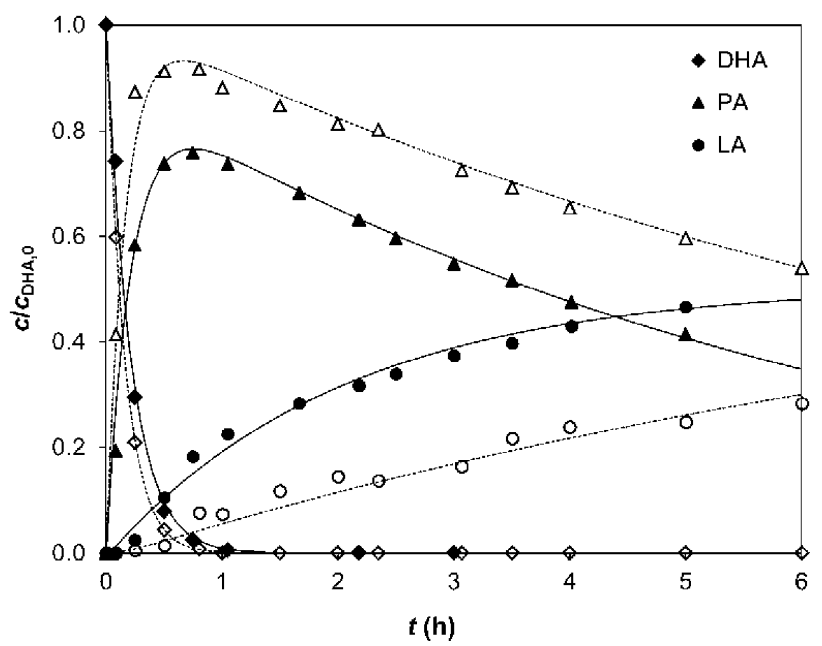

Fig. 6 - Comparison of $\mathrm{HCl}$ (blank data points/dashed lines) and $\mathrm{HCl}$ plus $\mathrm{Al}^{3+}$ (full data points/solid lines) catalysed lactic acid formation from dihydroxyacetone $\left(c_{D H A, 0}=0.56 \mathrm{~mol} \mathrm{~L} L^{-1}\right.$, $\left.c_{H C l}=1 \mathrm{~mol} \mathrm{~L}^{-1}, c_{A l}=0.06 \mathrm{~mol} \mathrm{~L}^{-1}, 99^{\circ} \mathrm{C}\right)$

\section{Catalysis with metal salts}

Comparison of different metal salts

For a catalyst screening, the soluble metal salts $\mathrm{Al}_{2}\left(\mathrm{SO}_{4}\right)_{3}, \mathrm{CuSO}_{4}, \mathrm{ZnSO}_{4}$, and $\mathrm{ZrOCl}_{2}$ were compared (Table 4). Experiments were performed with $0.56 \mathrm{~mol} \mathrm{~L}-1$ feed dihydroxyacetone at $99^{\circ} \mathrm{C}$.

Whereas $\mathrm{Al}_{2}\left(\mathrm{SO}_{4}\right)_{3}$ showed high catalytic activity and selectivity for lactic acid, the selectivity towards lactic acid with $\mathrm{ZnSO}_{4}$ and $\mathrm{ZrOCl}_{2}$ was low. The yield of lactic acid after six hours was $54 \%$ with $\mathrm{Al}_{2}\left(\mathrm{SO}_{4}\right)_{3}$ compared to $21 \%$ with $\mathrm{ZrOCl}_{2}$ when a metal ion concentration of $0.06 \mathrm{~mol} \mathrm{~L}^{-1}$ was used. It was $73 \%$ with $\mathrm{Al}_{2}\left(\mathrm{SO}_{4}\right)_{3}$ compared to $4 \%$ with $\mathrm{ZnSO}_{4}$ when stoichiometric metal ion concentration of $0.56 \mathrm{~mol} \mathrm{~L}^{-1}$ was used.
Table 4-Catalytic effect of various metal salts on lactic acid formation from dihydroxyacetone (reaction time: $1 \mathrm{~h} ; c_{D H A, 0}=c_{M e}=0.56 \mathrm{~mol} \mathrm{~L}{ }^{-1}, 99{ }^{\circ} \mathrm{C}$ )

\begin{tabular}{l|c|c|c|c}
\hline \multicolumn{1}{c|}{ Metal salt } & $\begin{array}{c}X_{\text {DHA }} \\
\%\end{array}$ & $\begin{array}{c}Y_{\mathrm{PA}} \\
\%\end{array}$ & $\begin{array}{c}Y_{\mathrm{LA}} \\
\%\end{array}$ & $\begin{array}{c}Y_{\mathrm{LA}}{ }^{[\mathrm{b}]} \\
\%\end{array}$ \\
\hline $\mathrm{Al}_{2}\left(\mathrm{SO}_{4}\right)_{3}{ }^{[\mathrm{a}]}$ & 63 & 21 & 22 & 73 \\
$\mathrm{Al}_{2}\left(\mathrm{SO}_{4}\right)_{3}$ & 97 & 15 & 57 & 77 \\
$\mathrm{Al}_{\left(\mathrm{NO}_{3}\right)_{3}}$ & 78 & 28 & 50 & 77 \\
$\mathrm{ZnSO}_{4}$ & 87 & 1 & 3 & 4 \\
$\mathrm{ZrOCl}_{2}{ }^{[\mathrm{a}]}$ & 100 & 2 & 18 & 21 \\
$\mathrm{CuSO}_{4}$ & n.a. & - & - & - \\
\hline
\end{tabular}

${ }^{[a]} c_{\mathrm{Me}}=0.14 \mathrm{~mol} \mathrm{~L}^{-1}{ }^{[\mathrm{b}]}$ reaction time: $6 \mathrm{~h}$

Minor amounts of isomeric glyceraldehyde were detected for aluminium salt catalysts. Glyceraldehyde was not detected with $\mathrm{CuSO}_{4}, \mathrm{ZnSO}_{4}$ and $\mathrm{ZrOCl}_{2}$

Even though the use of $\mathrm{ZnSO}_{4}$ resulted in dihydroxyacetone conversion of more than $85 \%$ after one hour, selectivity for lactic acid remained below $4 \%$. $\mathrm{ZnSO}_{4}$ dissolves in aqueous solution under acidic hydrolysis providing acidic media for dihydroxyacetone conversion to pyruvic aldehyde. The fact that pyruvic aldehyde was not detected in remarkable amounts accounts for a fast subsequent reaction. But side reactions were dominating and lactic acid formation was suppressed.

With $\mathrm{ZrOCl}_{2}$, dihydroxyacetone was converted within one hour. Lactic acid selectivity remained rather low at $21 \%$. Since pyruvic aldehyde was not detected in remarkable amounts, again by-product formation could be assumed by the material balance.

Lactic acid was not formed with $\mathrm{CuSO}_{4}$.

\section{Catalysis with the Lewis acid aluminium sulphate}

With respect to the high catalytic effect, high selectivity for lactic acid and advantageous dissolution properties, further experiments were performed with $\mathrm{Al}_{2}\left(\mathrm{SO}_{4}\right)_{3}$ as catalyst.

Two complementary effects are observed with $\mathrm{Al}_{2}\left(\mathrm{SO}_{4}\right)_{3}$. Firstly, $\mathrm{Al}_{2}\left(\mathrm{SO}_{4}\right)_{3}$ dissolves under strongly acidic hydrolysis providing acidic reaction conditions. High acidity of the aqueous reaction solution is essential for dehydration of dihydroxyacetone to pyruvic aldehyde. Secondly, the multivalent metal ion $\mathrm{Al}^{3+}$ catalyses the intramolecular Cannizzaro reaction of pyruvic aldehyde to form lactic acid. This may be attributed to complex formation of the intermediate pyruvic aldehyde and the metal ion. Rehydration of this complex leads to the formation of lactic acid and then the free catalyst. Lactic acid formation from pyruvic aldehyde is rate determining under acid catalysis with $\mathrm{HCl}$ (Table 2). 
Similar to the aluminium-catalysed formation of hydroxyacetic acid from glyoxal ${ }^{26}$, lactic acid formation from pyruvic aldehyde is a first order reaction with respect to pyruvic aldehyde. Experiments were performed with pyruvic aldehyde and the reaction kinetics was confirmed.

Representative conversion graphs for the $\mathrm{Al}^{3+}$ catalysed reaction of dihydroxyacetone to lactic acid are shown in Figure 7.

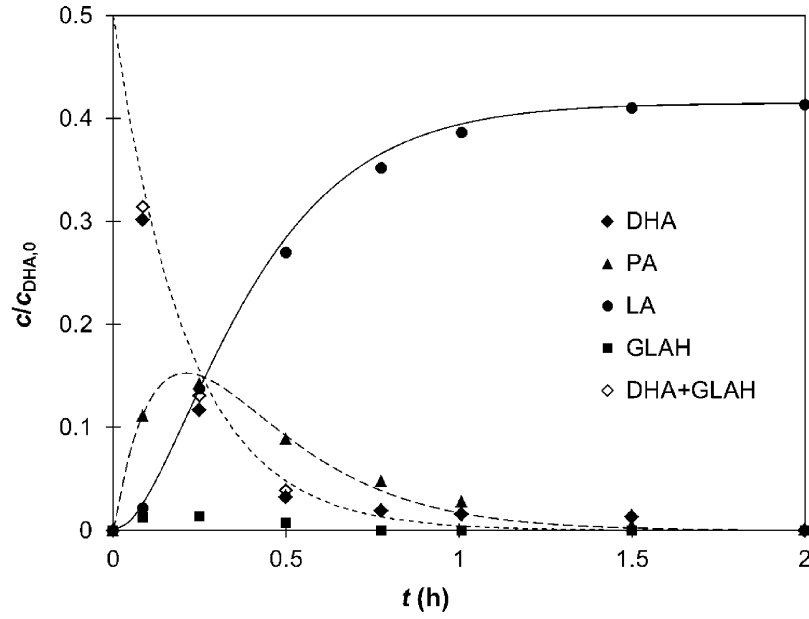

Fig. 7 - Course of dihydroxyacetone, pyruvic aldehyde, glyceraldehyde, and lactic acid concentrations for $\mathrm{Al}^{3+}$ catalysed conversion of dihydroxyacetone to lactic acid (catalyst: $\mathrm{Al}_{2}\left(\mathrm{SO}_{4}\right)_{3}$, $\left.c_{D H A, 0}=0.56 \mathrm{~mol} \mathrm{~L}{ }^{-1}, c_{A l}=0.83 \mathrm{~mol} \mathrm{~L}^{-1}, 99^{\circ} \mathrm{C}\right)$

Isomeric glyceraldehyde was detected at the beginning of the reaction. Both dihydroxyacetone and glyceraldehyde contributed to lactic acid formation. Opposite to the $\mathrm{HCl}$-catalysed reaction, dehydration of dihydroxyacetone to pyruvic aldehyde was rate-determining with the catalyst $\mathrm{Al}_{2}\left(\mathrm{SO}_{4}\right)_{3}$.

The initially transparent reaction solution changed colour to yellowish and finally dark brown with ongoing reaction time. This was also observed when performing the conversion with the catalyst $\mathrm{HCl}$. Oligo- and polymerization of pyruvic aldehyde and dihydroxyacetone may be indicated as the governing reason for colour change and formation of insoluble by-products. ${ }^{23}$

\section{Effect of the reaction temperature}

The effect of the reaction temperature on the aluminium-catalysed lactic acid formation was investigated in a temperature range of $70{ }^{\circ} \mathrm{C}$ to $99{ }^{\circ} \mathrm{C}$ (reflux boiling conditions) with $0.56 \mathrm{~mol} \mathrm{~L}^{-1}$ feed dihydroxyacetone. The molar ratio of feed $\mathrm{Al}^{3+} / \mathrm{di}$ hydroxyacetone was 1 .

As expected from the $\mathrm{HCl}$-catalysed reaction, lactic acid yields increased with increasing reaction temperature. Whereas the lactic acid yield after six hours was low $(10 \%)$ at $70{ }^{\circ} \mathrm{C}$, high yields of $78 \%$ were achieved at reflux boiling conditions $\left(99^{\circ} \mathrm{C}\right)$. Complete conversion of dihydroxyacetone was achieved within six hours at $99^{\circ} \mathrm{C}$. At $70{ }^{\circ} \mathrm{C}$, residual dihydroxyacetone was still $22 \%$ after six hours. At $99{ }^{\circ} \mathrm{C}$, maximum yields of pyruvic aldehyde of $30 \%$ after 15 minutes indicated a fast consecutive reaction to lactic acid.

No change in reaction mechanism was indicated from the Arrhenius' plot within the investigated temperature range. Table 5 lists the activation energies $E_{\mathrm{A}}$ and pre-exponential factors $A$ for the first $(\mathrm{DHA} \rightarrow \mathrm{PA})$ and second $(\mathrm{PA} \rightarrow \mathrm{LA})$ reaction step.

Table 5-Activation energy $E$ and pre-exponential factor $A$ for aluminium-catalysed conversion of dihydroxyacetone to lactic acid (catalyst: $\mathrm{Al}_{2}\left(\mathrm{SO}_{4}\right)_{3}, c_{D H A, 0}=c_{A l}=0.56 \mathrm{~mol} \mathrm{~L}^{-1}$ )

\begin{tabular}{l|c|c}
\hline & $A\left(\mathrm{~h}^{-1}\right)$ & $E_{\mathrm{A}}\left(\mathrm{kJ} \mathrm{mol}^{-1}\right)$ \\
\hline $1 . \mathrm{DHA} \rightarrow$ PA & $(4.39 \pm 0.01) \cdot 10^{13}$ & $93.5 \pm 0.2$ \\
$2 . \mathrm{PA} \rightarrow \mathrm{LA}$ & $(2.68 \pm 0.01) \cdot 10^{12}$ & $91.8 \pm 0.2$ \\
\hline
\end{tabular}

\section{Effect of aluminium sulphate concentration}

The effect of the $\mathrm{Al}_{2}\left(\mathrm{SO}_{4}\right)_{3}$ concentration on the rate of conversion was investigated by variation of the molar ratio of $\mathrm{Al}^{3+}$ to dihydroxyacetone from 0.01 to 1.5 . Feed concentration of dihydroxyacetone was $0.56 \mathrm{~mol} \mathrm{~L}^{-1}$ in the experiments. As expected, increasing $\mathrm{Al}^{3+}$ concentration resulted in the acceleration of lactic acid formation. Figure 8 shows the lactic acid yields for varying $\mathrm{Al}^{3+} /$ dihydroxyacetone feed ratio. The maximum lactic acid yield was $73 \%$. No difference in selectivity towards pyruvic aldehyde and lactic acid was observed for varying $\mathrm{Al}^{3+}$ concentration of 0.006 to $0.83 \mathrm{~mol} \mathrm{~L}^{-1}$.

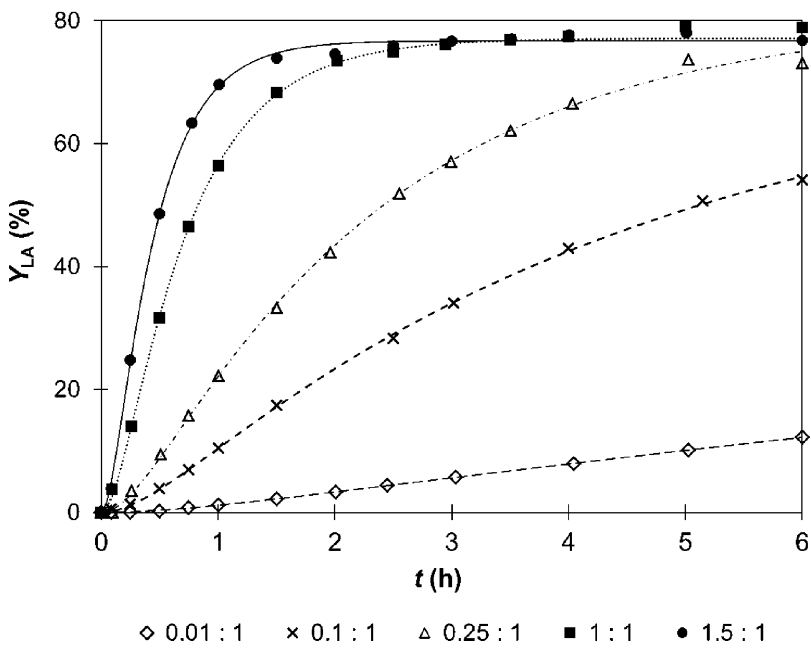

Fig. 8 - Effect of the molar feed ratio $\mathrm{Al}^{3+} /$ dihydroxyacetone on the formation of lactic acid from dihydroxyaceto-

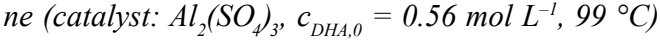


Rate constants $k_{1}$ and $k_{2}$ for different $\mathrm{Al}_{2}\left(\mathrm{SO}_{4}\right)_{3}$ concentrations are given in Table 6 . An almost linear correlation between $k_{1}$ and $k_{2}$ and the $\mathrm{Al}_{2}\left(\mathrm{SO}_{4}\right)_{3}$ concentration was observed. With increasing $\mathrm{Al}_{2}\left(\mathrm{SO}_{4}\right)_{3}$ concentration, the difference between $k_{1}$ and $k_{2}$ reduced. This may be explained by increasing acidity of the solution resulting from high $\mathrm{Al}_{2}\left(\mathrm{SO}_{4}\right)_{3}$ concentrations.

Table 6 -Rate constants $k_{1}$ and $k_{2}$ of the aluminium-catalysed conversion of dihydroxyacetone to lactic acid (catalyst: $\mathrm{Al}_{2}\left(\mathrm{SO}_{4}\right)_{3}, c_{D H A, 0}=0.56 \mathrm{~mol} \mathrm{~L}^{-1}$, $\left.99{ }^{\circ} \mathrm{C}\right)$

\begin{tabular}{c|c|c}
\hline $\begin{array}{c}c_{\mathrm{Al}} \\
\left(\mathrm{mol} \mathrm{L}^{-1}\right)\end{array}$ & $\begin{array}{c}k_{1} \\
\left(\mathrm{~h}^{-1}\right)\end{array}$ & $\begin{array}{c}k_{2} \\
\left(\mathrm{~h}^{-1}\right)\end{array}$ \\
\hline 0.006 & 0.10 & 0.30 \\
0.056 & 0.42 & 0.94 \\
0.14 & 0.89 & 1.2 \\
0.56 & 3.1 & 3.2 \\
0.84 & 4.7 & 4.8 \\
\hline
\end{tabular}

\section{Conclusions}

Synthesis of lactic acid from aqueous dihydroxyacetone solution is a promising approach for chemical production from bio-based precursors. Handling of aqueous reaction systems and integrated approaches including product separation are of prime importance for exploitation of biomass. Catalysis of the liquid phase reaction was investigated with Brønsted acids, acidic hydrolysing metal salts, and a combination thereof. Brønsted acids are often present in aqueous solutions of bio-based precursors.

Lactic acid formation favours high temperatures and strongly acidic operating conditions. Lactic acid yields of $83 \%$ were achieved when carrying out the reaction under reflux boiling conditions and the catalyst $\mathrm{HCl}$ in excess. Lactic acid formation from dihydroxyacetone proceeds via two consecutive reaction steps with pyruvic aldehyde serving as intermediate. Conversion of pyruvic aldehyde is rate controlling under acid catalysis. The rate of pyruvic aldehyde conversion is accelerated with catalytic amounts of multivalent $\mathrm{Al}^{3+}$ and $\mathrm{Sn}^{2+}$. The Lewis acid $\mathrm{Al}_{2}\left(\mathrm{SO}_{4}\right)_{3}$ provides both acidic reaction conditions for dehydration of dihydroxyacetone to pyruvic aldehyde and acceleration of lactic acid formation from pyruvic aldehyde. Both acid and $\mathrm{Al}^{3+}$ catalysis is promising for the synthesis of lactic acid from aqueous dihydroxyacetone solutions.

\section{ACKNOWLEDGEMENTS}

This research was partially supported by Sonja Larissegger, Jutta Krischan and Stefan Naderer during their project work at TU Graz. The authors also thank Herta Luttenberger for assistance with the HPLC, and Peter Stehring for comments that greatly improved the work. The authors furthermore gratefully acknowledge the support from NAWI Graz.

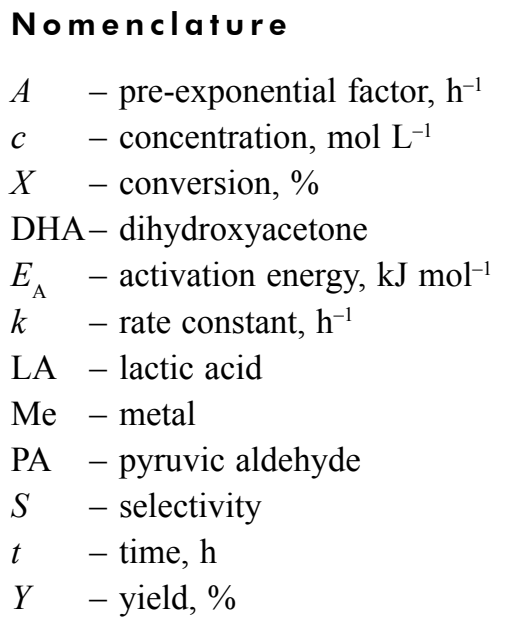

\section{References}

1. Werpy, T., Petersen, G., Technical Report No. DOE/GO102004-1992, National Renewable Energy Lab, Golden, CO, 2004

2. Malveda, M. P., Blagoev, M., Kumamoto, T, Lactic Acid, Its Salts and Esters. CEH Marketing Research Report, SRI Consulting, 2009.

3. Matsumoto, T., Yamamoto, H., Inoue, S., Selective formation of triose from formaldehyde catalyzed by thiazolium salt, J. Am. Chem. Soc. 106 (1984) 4829 doi: http://dx.doi.org/10.1021/ja00329a031

4. Kimura, H., Tsuto, K., Wakisaka, T., Kazumi, Y., Inaya, Y., Selective oxidation of glycerol on a platinum-bismuth catalyst, Appl. Catal. A 96 (1993) 217. doi: http://dx.doi.org/10.1016/0926-860X(90)80011-3

5. Kimura, H., Selective oxidation of glycerol on a platinum-bismuth catalyst by using a fixed bed reactor, Appl. Catal. A 105 (1993) 147. doi: http://dx.doi.org/10.1016/0926-860X(93)80245-L

6. Demirel, S., Lehnert, K., Lucas, M., Claus, P., Use of renewables for the production of chemicals: Glycerol oxidation over carbon supported gold catalysts, Appl. Catal. B 70 (2007) 637. doi: http://dx.doi.org/10.1016/j.apcatb.2005.11.036

7. Stehring, P., Lux, S., Hilber, T., Letonja P., Siebenhofer, M., Oxidation von Glycerin an Diamantelektroden, Chem. Ing. Tech. 80 (2008) 1387. doi: http://dx.doi.org/10.1002/cite.200750475

8. Tkaczuk, P., Elektrochemische Oxidation von Glycerin und Glycerinderivaten an einer Platin-Anode in verschiedenen Zelltypen, Shaker, Aachen, 1994.

9. Weber, $U$., Die elektrochemische Oxidation von Glycerin an unterschiedlichen Elektrodenmaterialien, Shaker, Aachen, 1994. 
10. Roquet, L., Belgsir, E. M., Leger, J.-M., Lamy, C., Kinetics and mechanisms of the electrocatalytic oxidation of glycerol as investigated by chromatographic analysis of the reaction products: potential and $\mathrm{pH}$ effects, Electrochim. Acta 39 (1994) 2387.

doi: http://dx.doi.org/10.1016/0013-4686(94)E0190-Y

11. Stehring, P., Lux, S., Letonja, P., Siebenhofer, M., Anodische Oxidation von Glycerin in einer Dünnschichtzelle, Chem. Ing. Tech. 81 (2009) 1224.

doi: http://dx.doi.org/10.1002/cite.200950037

12. Charney, $W$. (Schering Corporation), US Patent Appl. 4,076,589,28, Feb 1978.

13. Ohrem, H.-L., Westmeier, F. (Merck Patent GmbH.), US Patent Appl. 5,770,411, 23 Jun 1998.

14. Wethmar, M., Dechwer, W.-D., Semisynthetic culture medium for growth and dihydroxyacetone production by Gluconobacter oxydans, Biotechnol. Techniques 13 (1999) 283.

doi: http://dx.doi.org/10.1023/A:1008978903231

15. Prey, V., Berbalk, H., Steinbauer, E., Über die Bildung von Milchsäure aus Triosen durch Einwirkung von Säuren, 2. Mitteilung, Chemical Monthly 93 (1962) 237.

16. Pinkus, G., Über die Einwirkung von Benzhydrazid auf Glucose, Ber. dt. chem. Ges. 31 (1898) 31. doi: http://dx.doi.org/10.1002/cber.18980310108

17. Lookhart, G. L., Feather, M. S., Acid-catalyzed isomerization and dehydration of DL-glyceraldehyde and 1,3-dihydroxy-2-propanone, Carbohydr. Res. 60 (1978) 259. doi: http://dx.doi.org/10.1016/S0008-6215(78)80033-0

18. West, R. M., Holm, M. S., Saravanamurugan, S., Xiong, J., Beversdorf, Z., Taarning, E., Christensen, C. H., Zeolite H-USY for the production of lactic acid and methyl lactate from C-3-sugars, J. Catal. 269 (2010) 122. doi: http://dx.doi.org/10.1016/j.jcat.2009.10.023
19. Zhang, Z., Zhao, Z., Hydroxyapatite Supported Lewis Acid Catalysts for the Transformation of Trioses in Alcohols, Chin. J. Catal. 32 (2011) 70. doi: http://dx.doi.org/10.1016/S1872-2067(10)60162-3

20. Li, L., Stroobants, C., Lin, K., Jacobs, P. A., Sels, B. F., Pescarmona, $P$. P., Selective conversion of trioses to lactates over Lewis acid heterogeneous catalysts, Green Chem. 13 (2011) 1175. doi: http://dx.doi.org/10.1039/c0gc00923g

21. Wang, J., Masui, Y., Onaka, M., Conversion of triose sugars with alcohols to alkyl lactates catalyzed by Brønsted acid tin ion-exchanged montmorillonite, Appl. Catal. B 107 (2011) 135 . doi: http://dx.doi.org/10.1016/j.apcatb.2011.07.006

22. Bicker, M., Endres, S., Ott, L., Vogel, H., Catalytical conversion of carbohydrates in subcritical water: A new chemical process for lactic acid production, J. Mol. Catal. A 239 (2005) 151 .

doi: http://dx.doi.org/10.1016/j.molcata.2005.06.017

23. Rasrendra, C. B., Fachri, B. A., Makertihartha, I. G. B. N. Adisasmito, S., Heeres, H. J., Catalytic conversion of dihydroxyacetone to lactic acid using metal salts in water, Chem. Sus. Chem. 4 (2011) 768. doi: http://dx.doi.org/10.1002/cssc.201000457

24. Kobayashi, Y., Igarashi, T., Takahashi, H., Higasi, K., Infrared and Raman studies of the dimeric structures of 1,3-dihydroxyacetone, D-(+)- and DL-glyceraldehyde, J. Mol. Struct. 35 (1976) 85. doi: http://dx.doi.org/10.1016/0022-2860(76)80104-4

25. Hahn, G. C., Schales, O., Selbstkondensation des Methylglyoxals, Ber. dt. chem. Ges. 67 (1934) 1816.

26. Kiyoura, T., Kogure, Y., Synthesis of hydroxyacetic acid and its esters from glyoxal catalyzed by multivalent metal ions, Appl. Catal. 156 (1997) 97. doi: http://dx.doi.org/10.1016/S0926-860X(96)00414-0 